\title{
Comparison of post-operative ICU sedation between dexmedetomidine and propofol in Indian population
}

\author{
Prerana N Shah, Vaibhao Dongre, Vijay Patil, Sarla Pandya, Ashish Mungantiwar ${ }^{1}$, \\ Amol Choulwar ${ }^{1}$
}

Context: Critically ill patients requiring mechanical ventilation frequently need sedatives and analgesics to facilitate their care. Dexmedetomidine, a short-acting alpha-2-agonist, possesses anxiolytic, anesthetic, hypnotic, and analgesic properties. Aims: The objective of this study was to evaluate the efficacy and safety of dexmedetomidine in comparison to propofol in the management of sedation for post-operative intensive care unit (ICU) patients, as a sedative agent. Settings and Design: Teaching hospital, A phase III, prospective, open, randomized and comparative. Materials and Methods: Thirty patients who were ambulatory and who required the post-operative mechanical ventilation or post-operative sedation were enrolled, in which 15 patients received Dexmedetomidine and remaining 15 patients received propofol. All these patients were treated for the period of 8 to 24 h. Statistical Analysis Used: Data were analyzed using Student's $t$-test and Chi-square test. The value of $P<0.05$ was considered as statistically significant. Results: Demographic data were comparable. Pulse rate, respiratory rate and blood pressure were comparable. Depth of sedation and extubation time were similar. To maintain analgesia throughout the study period, patients receiving propofol infusions required significantly more analgesics than patients receiving Dexmedetomidine. Conclusions: Dexmedetomidine appears to be a safe and acceptable ICU sedative agent when both the clinician's and patient's perspectives are considered.

Keywords: Dexmedetomidine, intensive care unit sedation, propofol

\section{Introduction}

Critically ill patients requiring mechanical ventilation frequently need sedatives and analgesics to facilitate their care. ${ }^{[1]}$ There is an increasing body of evidence showing that protocol-based strategies do not only reduce variation and cost of intensive care medicine, but also improve morbidity and mortality of critically ill patients ${ }^{[2]}$. Analgesia and sedation are among these areas where considerable variations exist among practitioners $^{[3,4]}$. The concepts of analgesia and sedation

From:

Department of Anaesthesiology, Seth G S Medical College \& KEM Hospital, Mumbai, 'Medical Services, Macleods Pharmaceuticals Ltd, Mumbai, India

Correspondence:

Dr. Prerana N. Shah, 73 B, Varma Villa, Vitthalbhai Road, Vile Parle West, Mumbai- 400 056, Maharashtra, India.

E-mail: pps@kem.edu

\begin{tabular}{|l|}
\hline Access this article online \\
\hline Website: www.ijccm.org \\
\hline DOI: 10.4103/0972-5229.132485 \\
\hline Quick Response Code: \\
\hline
\end{tabular}

in intensive care medicine have changed considerably over the last decade. Deep sedation is no longer the standard practice for most patients as it prolongs weaning from mechanical ventilation and the length of ICU stay and potentially increases morbidity ${ }^{[5,6]}$. On the other hand, inadequate sedation can result in anxiety, agitation and in recall of stressful experience in the post-ICU phase ${ }^{[7]}$. Therefore, analgesics and sedatives must be carefully titrated to the individual needs ${ }^{[8]}$.

Inappropriate sedative use in the intensive-care unit (ICU) is associated with adverse outcomes, including patient discomfort, excessive sedation, longer ICU and hospital stays, an increased incidence of ventilator-associated pneumonia, and greater hospital costs. ${ }^{[1]}$ The use of propofol or midazolam is recommended ${ }^{[1]}$ As pain is often the culprit in agitation, an opioid analgesic is recommended, in 
addition to the previously mentioned agents, to provide adequate analgesia. ${ }^{[1]}$ However, propofol lacks analgesic properties, and its usage is often limited by hypotension and respiratory depression. ${ }^{[1]}$ Benzodiazepine is also associated with respiratory depression and the potential for the drug to accumulate, leading to a prolonged recovery period. Dexmedetomidine is a sedative with high affinity for a2-adrenoreceptor ${ }^{[9]}$. It sedates via interaction with the locus ceruleus, and has less effect on arousability and patient interaction ${ }^{[10,11]}$. In post-surgical patients, dexmedetomidine does not interfere with respiration rate, or arterial oxygenation and carbon dioxide pressure ${ }^{[12]}$.The objective of this study was to investigate and evaluate the efficacy and safety of dexmedetomidine in comparison to propofol in the management of sedation for post-operative intensive care unit (ICU) patients, as a sedative agent.

This trial was designed in the Indian population to evaluate the efficacy and tolerability of Dexmedetomidine versus propofol alone in the management of sedation for the period after any major surgery.

\section{Materials and Methods}

The objective of this prospective and randomized clinical study was to investigate and evaluate the efficacy and safety of dexmedetomidine in comparison to propofol in the management of sedation for post-operative ICU patients, as a sedative agent.

Sample size was calculated using SAS 9.1.3. The data used to obtain the sample size were derived from a published clinical trial of dexmedetomidine versus propofol when used for intraoperative sedation. ${ }^{[13]}$ As per the SAS output, 26 patients per group is adequate enough for $90 \%$ power or to achieve statistically significant results. Hence, taking into consideration dropouts for this study, a total of 100 patients were included in the study. In our center 30 patients were enrolled, who required the post-operative mechanical ventilation or post-operative sedation, in which 15 patients received Dexmedetomidine and remaining 15 patients received propofol. All patients were treated for the period of 8-24 hours. Data presented here is of only 30 patients done at our centre. Patients undergoing surgery on an inpatient basis, with age from 18 to 70 years of both gender and willing to give the consent were included in the study.

Patients currently being treated or were treated within the last 30 days with alpha- 2 agonist and blockers, with central nervous system (CNS), cardio vascular system (CVS), liver, renal problems, history of obstructive sleep apnea, pregnant or lactating females, in whom, propofol would be given for anesthesia were excluded from the study.

After Institutional Ethics Committee approval and a written informed consent from patient or relatives, the patients were enrolled in thestudy. As per randomization, wheneach patient had VAS $\geq 4$ and Ramsay sedation score $\leq 2$, they received either dexmedetomidine or propofol and were treated for the period of $24 \mathrm{~h}$. Dexmedetomidine was administrated by a loading dose of injection with $1 \mathrm{mcg} / \mathrm{kg}$ over $10 \mathrm{~min}$, followed by a maintenance infusion of $0.2-0.7 \mathrm{mcg} / \mathrm{kg} / \mathrm{h}$. The rate of the maintenance infusion was adjusted to achieve the desired level of sedation. Propofol was started at $5 \mathrm{mcg} / \mathrm{kg} / \mathrm{min}(0.3 \mathrm{mg} / \mathrm{kg} / \mathrm{h})$. Theinfusionratewasincreased by increments of $5-10 \mathrm{mcg} / \mathrm{kg} / \mathrm{min}(0.3-0.6 \mathrm{mg} / \mathrm{kg} / \mathrm{h})$ until the desired level of sedation was achieved. A minimum period of 5 min between adjustments was allowed for the onset of peak drug effect.

\section{Cardio respiratory variables}

Pulse-rate, respiratory rate, blood pressure (Systolic/ Diastolic), mean arterial pressure and SPO2; Ramsay sedation scale, VAS, recovery time from sedation and analgesic requirement were noted. Efficacy was assessed to achieve Ramsay score of 2-3 after the surgery as early as possible. RSS is a six-item observer-rated scale to assess the sedation states, in which Score 1 represents anxious or restless or both, 2 co-operative, orientated and tranquil, 3 responding to commands, 4 brisk response to stimulus, 5 sluggish response to stimulus and 6 represents no response to stimulus. VAS is a 0-10 observer-rated scale to assess the pain in which score 0 means no pain and score 10 means severe pain.

The primary efficacy parameter was to evaluate cardio-respiratory end points at equi-sedative doses of Dexmedetomidine and propofol in the ICU. Patient's global assessment of pain intensity (0-10 VAS), global assessments of the treatment efficacy by the patient and by the investigator were also noted. If VAS $>4$, analgesia (fentanyl) was given.

\section{Statistics}

Data were analyzed using Student's $t$-test and Chi-square test. The value of $P<0.05$ was considered as statistically significant.

\section{Results}

All the 30 patients completed the study. Table 1 shows that age and weight were comparable. In Dexmedetomidine group, 6 out of 15 were male. In propofol group, 10 out of 15 were male. 


\section{Baseline characteristics}

Table 2 shows that the mean pulse-rate, respiratory rate, blood pressure between the groups was not statistically significant $(P>0.05)$. Table 3 shows comparable laboratory parameters before and after the drug. Table 4 shows that over the whole study period, the mean RSS was between 2-4 and 2-3 for Dexmedetomidine and propofol groups respectively. There was no statistical significant difference between the two groups throughout the study period. Table 5

\begin{tabular}{lcc}
\hline Table I: Demography & & \\
\hline Parameters & Dexmedetomidine & Propofol \\
\hline No. of patients & 15 & 15 \\
Age (years) Mean \pm SD & $49.5 \pm 14.13$ & $49.09 \pm 17.17$ \\
Weight (Kg) Mean \pm SD & $49.23 \pm 8.86$ & $51.39 \pm 9.02$ \\
Gender & & \\
$\quad$ Male & 6 & 10 \\
Female & 9 & 5 \\
\hline SD: Standard deviation & &
\end{tabular}

\begin{tabular}{|c|c|c|c|c|}
\hline \multirow[t]{2}{*}{ Parameters } & \multicolumn{2}{|c|}{ Dexmedetomidine } & \multicolumn{2}{|c|}{ Propofol } \\
\hline & $\begin{array}{c}\text { Pre- } \\
\text { operative }\end{array}$ & $\begin{array}{c}\text { Post- } \\
\text { operative }\end{array}$ & $\begin{array}{c}\text { Pre- } \\
\text { operative }\end{array}$ & $\begin{array}{c}\text { Post- } \\
\text { operative }\end{array}$ \\
\hline $\begin{array}{l}\text { Pulse-rate } \\
\text { (min) }\end{array}$ & $75.87 \pm 11.13$ & $83.53 \pm 16.70$ & $88.67 \pm 15.48$ & $94.58 \pm 16.15$ \\
\hline $\begin{array}{l}\text { Respiratory } \\
\text { rate (min) }\end{array}$ & $16.53 \pm 3.83$ & $17.07 \pm 3.47$ & $17.25 \pm 3.58$ & $20 \pm 4.0$ \\
\hline $\begin{array}{l}\text { Systolic } \\
\text { blood } \\
\text { pressure } \\
(\mathrm{mmHg})\end{array}$ & $124.2 \pm 14.86$ & $129.47 \pm 25.12$ & $122.83 \pm 18.23$ & $119.08 \pm 9.29$ \\
\hline $\begin{array}{l}\text { Diastolic } \\
\text { blood } \\
\text { pressure } \\
(\mathrm{mmHg})\end{array}$ & $78.53 \pm 8.81$ & $79.07 \pm 10.78$ & $76.83 \pm 6.55$ & $76.25 \pm 7.83$ \\
\hline $\begin{array}{l}\text { Mean } \\
\text { arterial } \\
\text { pressure }\end{array}$ & $88 \pm 10.65$ & $91.46 \pm 11.22$ & $91.75 \pm 9.03$ & $88.36 \pm 5.41$ \\
\hline
\end{tabular}

MAP: Mean arterial pressure shows the comparison of severity of pain through VAS among the two groups. Table 6 shows that, over the whole study period, the mean VAS score was maintained between 2-3.5 and 2-3 for dexmedetomidine and propofol groups respectively. However, patients receiving propofol infusions required additional analgesics than patients receiving dexmedetomidine. Fentanyl required in patients receiving propofol infusion was 125 (100-150) mcg. No adverse event was observed in this study.

\section{Efficacy assessment}

As shown in Table 7, with respect to patients assessment for efficacy, nine patients (i.e., 60\%) out of 15 in dexmedetomidine group had shown excellent rating where as none of the patients in propofol group has shown excellent rating, in addition to excellent rating $6(40 \%)$ and $10(66.67 \%)$ patients had given "Good" rating and 0 and $5(33.33 \%)$ patients had given "Poor" rating on treatment with dexmedetomidine and propofol therapy, respectively.

According to investigators, assessment for efficacy represented in ten patients $(66.67 \%)$ out of 15 in dexmedetomidine group had shown excellent rating as compared to $2(13.33 \%)$ patients in propofol group, whereas $5(33.33 \%)$ and $9(60 \%)$ patients had given "Good" rating and 0 and 4 (26.67\%) patients had given "Poor" rating on treatment with dexmedetomidine and propofol therapy, respectively.

\section{Safety assessment}

According to investigators, assessment for safety, $9(60 \%)$ and $3(20 \%)$ patients had given "Excellent" rating, whereas $6(40 \%)$ and $8(53.33 \%)$ patients had given "Good" rating and $0(0 \%)$ and $4(26.67 \%)$ patients had given "Poor" rating upon treatment with dexmedetomidine and propofol, respectively. This is depicted in Table 8.

\section{Table 3: Laboratory parameters}

\begin{tabular}{|c|c|c|c|c|}
\hline \multirow[t]{2}{*}{ Parameters } & \multicolumn{2}{|c|}{ Dexmedetomidine } & \multicolumn{2}{|c|}{ Propofol } \\
\hline & Pre-operative & Post-operative & Pre-operative & Post-operative \\
\hline Hemoglobin (g) & $10.37 \pm 2.30$ & $10.73 \pm 1.45$ & $\mid 1.35 \pm 2.5 \mathrm{I}$ & $11.59 \pm 2.22$ \\
\hline White blood count (cu mm) & $11605 \pm 6232$ & $12252 \pm 3826.74$ & $12390.0 \pm 4680.6$ & $13733.3 \pm 5268.2$ \\
\hline Erythrocyte sedimentation rate $(\mathrm{mm} / \mathrm{h})$ & $22 \pm 3.26$ & $19.5 \pm 7.46$ & $75 \pm 0.0$ & $63.8 \pm 37.59$ \\
\hline Platelet count (Cu mm) & $269250 \pm|3679|$ & $192428 \pm 81983.4$ & $245000 \pm 103590$ & $250645.4 \pm 13588$ \\
\hline Aspartate transaminase (U/L) & $55.5 I \pm 60.32$ & $46.79 \pm 41.09$ & $50.37 \pm 31.83$ & $50.04 \pm 33.93$ \\
\hline Alanine transaminase $(\mathrm{U} / \mathrm{L})$ & $39.02 \pm 47.53$ & $38.27 \pm 38.5 I$ & $43.30 \pm 32.71$ & $46.70 \pm 34.29$ \\
\hline Blood urea nitrogen (BUN) (Mg/DI) & $9.28 \pm 3.60$ & $8.85 \pm 3.87$ & $8.95 \pm 2.63$ & $9.17 \pm 3.03$ \\
\hline Serum creatinine $(\mathrm{Mg} / \mathrm{DI})$ & $0.81 \pm 0.18$ & $0.81 \pm 0.12$ & $0.84 \pm 0.16$ & $0.87 \pm 0.21$ \\
\hline Serum uric acid (Mg/DI) & $3.27 \pm 0.82$ & $3.28 \pm 1.03$ & $3.67 \pm 1.05$ & $3.39 \pm 0.62$ \\
\hline Total bilirubin (Mg/DI) & $0.68 \pm 0.22$ & $\mathrm{I} .3 \mathrm{I} \pm 2.39$ & $0.98 \pm 0.56$ & $1.39 \pm 1.15$ \\
\hline Electro cardiography & Normal & Normal & Normal & Normal \\
\hline Chest X-ray & Normal & Normal & Normal & Normal \\
\hline
\end{tabular}

BUN: Blood urea nitrogen 


\begin{tabular}{lcc}
\hline \multicolumn{2}{l}{ Table 4: Ramsay sedation scale } \\
\hline Time point & \multicolumn{2}{c}{ Ramsay sedation score } \\
\cline { 2 - 3 } & Dexmedetomidine & Propofol \\
\hline $20 \mathrm{~min}$ & $3.20 \pm \mathrm{I} .32$ & $2.4 \mathrm{I} \pm \mathrm{I} .38$ \\
$\mathrm{I.5 \textrm {h }}$ & $2.86 \pm \mathrm{I} .02$ & $2.66 \pm 0.62$ \\
$2.5 \mathrm{~h}$ & $2.40 \pm 0.48$ & $2.50 \pm 0.64$ \\
$4 \mathrm{~h}$ & $2.40 \pm 0.48$ & $2.66 \pm 0.62$ \\
$6 \mathrm{~h}$ & $2.40 \pm 0.6 \mathrm{I}$ & $2.58 \pm 0.64$ \\
$10 \mathrm{~h}$ & $2.38 \pm 0.62$ & $2.41 \pm 0.64$ \\
$15 \mathrm{~h}$ & $2.23 \pm 0.42$ & $2.27 \pm 0.6 \mathrm{I}$ \\
$2 \mathrm{I} \mathrm{h}$ & $2.15 \pm 0.36$ & $2.27 \pm 0.6 \mathrm{I}$ \\
$24 \mathrm{~h}$ & $2.15 \pm 0.36$ & $2.09 \pm 0.5 \mathrm{I}$ \\
\hline
\end{tabular}

\section{Table 5: VAS}

\begin{tabular}{lcc}
\hline Time point & \multicolumn{2}{c}{ Visual analogue score } \\
\cline { 2 - 3 } & Dexmedetomidine & Propofol \\
\hline $20 \mathrm{~min}$ & $\mathrm{I} .7 \mathrm{I} \pm \mathrm{I} .33$ & $* 3.70 \pm 2.63$ \\
$\mathrm{I.5 \textrm {h }}$ & $\mathrm{I} .78 \pm 1.26$ & $2.25 \pm 1.2 \mathrm{I}$ \\
$2.5 \mathrm{~h}$ & $2.00 \pm 1.55$ & $2.45 \pm 1.43$ \\
$4 \mathrm{~h}$ & $2.42 \pm 1.54$ & $2.45 \pm 1.15$ \\
$6 \mathrm{~h}$ & $2.35 \pm 1.49$ & $2.45 \pm 1.15$ \\
$10 \mathrm{~h}$ & $1.91 \pm 1.03$ & $2.35 \pm 0.97$ \\
$15 \mathrm{~h}$ & $2.16 \pm 1.04$ & $2.55 \pm 0.80$ \\
$2 \mathrm{I} \mathrm{h}$ & $2.43 \pm 0.76$ & $2.50 \pm 1.02$ \\
$24 \mathrm{~h}$ & $2.48 \pm 0.74$ & $2.55 \pm 1.20$ \\
\hline$* P<0.05$ there was statistical significant difference between the two groups
\end{tabular}

Table 6: Overall assessment of efficacy by patient

\begin{tabular}{lccccc}
\hline Efficacy & \multicolumn{2}{c}{ Dexmedetomidine } & & \multicolumn{2}{c}{ Propofol } \\
\cline { 2 - 3 } \cline { 6 - 7 } & No & & & No & $\%$ \\
\hline Excellent & 09 & 60 & & 00 & 00 \\
Good & 06 & 40 & & 10 & 66.67 \\
Poor & 00 & 00 & & 05 & 33.33 \\
Total & 15 & 100 & & 15 & 100 \\
\hline
\end{tabular}

\section{Discussion}

This trial is an observational, therapeutic use study investigating the effect of dexmedetomidine versus propofol in patients requiring sedation in intensive care procedures. Sedatives are used in most patients undergoing various surgeries during the post-operative period to reduce anxiety during rewarming and to reduce cardiovascular instability. Articles show that using protocols to guide sedation in various groups of critically ill patients decreases the duration of both mechanical ventilation and ICU stay. ${ }^{[1]}$

Dexmedetomidine is as effective as propofol for producing and maintaining adequate short-term sedation of critically ill, mechanically ventilated patients. ${ }^{[1]}$ The benefits of dexmedetomidine over currently available sedative agents include its lack of respiratory depression and its ability to decrease the need for opioid analgesics. ${ }^{[1]}$
Table 7: Overall assessment of efficacy by investigators

\begin{tabular}{lccccc}
\hline Efficacy & \multicolumn{2}{c}{ Dexmedetomidine } & & \multicolumn{2}{c}{ Propofol } \\
\cline { 2 - 3 } & No & & & No & $\%$ \\
\hline Excellent & 10 & 66.67 & & 02 & 13.33 \\
Good & 05 & 33.33 & & 09 & 60.00 \\
Poor & 00 & 00 & & 04 & 26.67 \\
Total & 15 & 100 & & 15 & 100 \\
\hline
\end{tabular}

Table 8: Overall assessment of safety by investigators

\begin{tabular}{lccccc}
\hline Safety by investigator & \multicolumn{2}{c}{ Dexmedetomidine } & & \multicolumn{2}{c}{ Propofol } \\
\cline { 2 - 3 } \cline { 6 - 7 } & No & $\%$ & & No & $\%$ \\
\hline Excellent & 09 & 60 & & 03 & 20.00 \\
Good & 06 & 40 & & 08 & 53.33 \\
Poor & 00 & 00 & & 04 & 26.67 \\
Total & 15 & 100 & & 15 & 100 \\
\hline
\end{tabular}

The present randomized, open study demonstrated that both infusions of dexmedetomidine and propofol produced sedation, and significant analgesia. Cardiovascular stability and respiratory function were both well maintained. There is a growing interest in the use of $\alpha 2$-adrenoceptor agonists like dexmedetomidine as it has a shorter half-life and has additional analgesic properties and maintains cardio respiratory function. ${ }^{[1]}$ Finally, antagonists to the effects of $\alpha 2$-adrenoceptor agonists have been described that make quick reversal of sedation an option. ${ }^{[14]}$ These properties may prove useful for post-operative or intensive care unit sedation. A rise in blood pressure may occur $1 \mathrm{~min}$ after the bolus and is attributed to the direct effects of $\alpha 2$-adrenoceptor stimulation of vascular smooth muscle. Dexmedetomidine does not appear to have any direct effects on the heart ${ }^{[15]}$. A biphasic cardiovascular response has been described after the application of dexmedetomidine ${ }^{[16-18]}$. The administration of a bolus of $1 \mathrm{mcg} / \mathrm{kg}$ dexmedetomidine initially results in a transient increase of the blood pressure and a reflex decrease in heart rate, especially in younger, healthy patients $^{[17]}$. The initial reaction can be explained by the peripheral á2B-adrenoceptor stimulation of vascular smooth muscle and can be attenuated by a slow infusion over 10 or more minutes.

Even at slower infusion rates, however, the increase in mean arterial pressure over the first 10 minutes was shown to be in the range of $7 \%$, with a decrease in heart rate between $16 \%$ and $18 \%{ }^{[18]}$. The initial response lasts for 5 to 10 minutes and is followed by a decrease in blood pressure of approximately $10 \%$ to $20 \%$ below baseline and a stabilization of the heart rate, also below baseline values; both of these effects are caused by the inhibition of the central sympathetic outflow overriding the direct stimulating effects ${ }^{[19]}$. Another possible explanation for 
the subsequent heart rate decrease is the stimulation of the presynaptic á2-adrenoceptor, leading to a decreased norepinephrine release ${ }^{[20]}$. The application of a single high dose of dexmedetomidine reduced norepinephrine release by as much as $92 \%$ in young healthy volunteers ${ }^{[21]}$. The release of epinephrine is also reduced by the same amount ${ }^{[22]}$. This seems to be more important than either central á2-adrenoceptor agonism or non-á adrenaline imidazole- preferring receptors in effecting the change ${ }^{[19]}$.

Dexmedetomidine is associated with little respiratory depression. This study confirmed a lack of a clinically significant respiratory effect. Belleville et al. ${ }^{[23]}$ reported that dexmedetomidine could be associated with episodes of obstructive apnea, and this was increasingly common at doses of 1 and $2 \mathrm{mg} / \mathrm{kg}$ that were given for 2 minutes and presumably associated with a rapid increase in sedation. Obstructive apnea was not evident in our study. An obstruction resulting in apnea is more likely related to the deep sedation and oral/pharyngeal anatomic events that are common to deep sleep. These properties might prove to be useful in a post-operative setting or in the intensive care unit. Previous studies have reported attenuation of hypertension and tachycardia in response to laryngoscopy and intubation by dexmedetomidine and clonidine. ${ }^{[24-26]}$ Dexmedetomidine has an alpha-2 to alpha-1 receptor selectivity ratio that is 10 times greater than that of clonidine and has a significantly shorter elimination half-life. ${ }^{[27]}$

\section{Conclusion}

In the present study, dexmedetomidine appears to be a safe and acceptable ICU sedative agent when both the clinician's and patient's perspectives are considered. Depth of sedation is similar to that given by propofol and the extubation time is equally rapid, despite the longer elimination half-life of dexmedetomidine. The cardiovascular respiratory variables of patients sedated with dexmedetomidine are similar to that of patients sedated with equipotent doses of propofol. These properties, combined with the analgesic qualities and lack of respiratory depression seen with dexmedetomidine, have advantages for patients at risk from myocardial ischemia.

In conclusion; dexmedetomidine therapy could be used safely and effectively, in post-operative ICU as sedative and analgesic agent.

\section{Acknowledgment}

We acknowledge Macleods Pharmaceuticals Ltd for funding the clinical trial.

\section{References}

1. Coursin DB, Coursin DB, Maccioli GA. Dexmedetomidine. Curr Opin Crit Care 2001;7:221-6.

2. Holcomb BW, Wheeler AP, Ely EW. New ways to reduce unnecessary variation and improve outcomes in the intensive care unit. Curr Opin Crit Care 2001; 7:304-11.

3. Rhoney DH, Murry KR. National survey on the use of sedatives and neuromuscular blocking agents in the pediatric intensive care unit. Pediatr Crit Care Med 2002;3:129-33.

4. Rhoney DH, Murry KR. National survey of the use of sedating drugs, neuromuscular blocking agents, and reversal agents in the intensive care unit. J Intensive Care Med 2003;18:139-45.

5. Schweickert WD, Gehlbach BK, Pohlman AS, Hall JB, Kress JP. Daily interruption of sedative infusions and complications of critical illness in mechanically ventilated patients. Crit Care Med 2004;32:1272-76.

6. Brook AD, Ahrens TS, Schaiff R, Prentice D, Sherman G, Shannon W, Kollef MH. Effect of a nursing-implemented sedation protocol on the duration of mechanical ventilation. Crit Care Med 1999;27:2609-15.

7. Woods JC, Mion LC, Connor JT, Viray F, Jahan L, Huber C, et $a l$. Severe agitation among ventilated medical intensive care unit patients: Frequency, characteristics and outcomes. Intensive Care Med 2004;30:1066-72.

8. Jacobi J, Fraser GL, Coursin DB, Riker RR, Fontaine D, Wittbrodt ET, et al. Clinical practice guidelines for the sustained use of sedatives and analgesics in the critically ill adult. Crit Care Med 2002;30:119-41.

9. Virtanen R, Savola JM, Saano V, Nyman L. Characterization of the selectivity, specificity and potency of medetomidine as an alpha 2-adrenoceptor agonist. Eur J Pharmacol 1988;150:9-14

10. Hall JE, Uhrich TD, Barney JA, Arain SR, Ebert TJ. Sedative, amnestic, and analgesic properties of small-dose dexmedetomidine infusions. Anesth Analg 2000;90:699-705.

11. Venn RM, Grounds RM. Comparison between dexmedetomidine and propofol for sedation in the intensive care unit: Patient and clinician perceptions. Br J Anaesth 2001;87:684-90

12. Venn RM, Hell J, Grounds RM. Respiratory effects of dexmedetomidine in the surgical patient requiring intensive care. Crit Care 2000; 4:302-08.

13. Arain SR, Ebert TJ. The efficacy, side effects, and recovery characteristics of dexmedetomidine versus propofol when used for intraoperative sedation. Anesth Analg 2002;95:461-6

14. Scheinin H, Aantaa R, Anttila M, Hakola P, Helminen A, Karhuvaara S. Reversal of the sedative and sympatholytic effects of dexmedetomidine with a specific alpha2-adrenoceptor antagonist atipamezole: A pharmacodynamic and kinetic study in healthy volunteers. Anesthesiology 1998;89:574-84.

15. Housmans PR. Effects of dexmedetomidine on contractility, relaxation, and intracellular calcium transients of isolated ventricular myocardium. Anesthesiology 1990;73:919-922.

16. Dyck JB, Maze M, Haack C, Vuorilehto L, Shafer SL. The pharmacokinetics and hemodynamic effects of intravenous and intramuscular dexmedetomidine hydrochloride in adult human volunteers. Anesthesiology 1993;78:813-820.

17. Bloor BC, Ward DS, Belleville JP, Maze M. Effects of intravenous dexmedetomidine in humans. II. Hemodynamic changes. Anesthesiology $1992 ; 77: 1134-42$

18. Hall JE, Uhrich TD, Barney JA, Arain SR, Ebert TJ. Sedative, amnestic, and analgesic properties of small-dose dexmedetomidine infusions. Anesth Analg 2000; 90:699-705.

19. Xu H, Aibiki M, Seki K, Ogura S, Ogli K. Effects of dexmedetomidine, an alpha 2-adrenoceptor agonist, on renal sympathetic nerve activity, blood pressure, heart rate and central venous pressure in urethane-anesthetized rabbits. J Auton Nerv Syst 1998; 71:48-54.

20. Aantaa R, Kanto J, Scheinin M, Kallio A, Scheinin H. Dexmedetomidine, an alpha 2-adrenoceptor agonist, reduces anesthetic requirements for patients undergoing minor gynecologic surgery. Anesthesiology 1990; 73:230-35.

21. Kallio A, Scheinin M, Koulu M, Ponkilainen R, Ruskoaho H, Viinamaki O, et al. Effects of dexmedetomidine, a selective alpha 2 -adrenoceptor agonist, on hemodynamic control mechanisms. Clin 
Pharmacol Ther $1989 ; 46: 33-42$.

22. Scheinin B, Lindgren L, Randell T, Scheinin H, Scheinin M. Dexmedetomidine attenuates sympathoadrenal responses to tracheal intubation and reduces the need for thiopentone and perioperative fentanyl. Br J Anaesth 1992; 68:126-131.

23. Belleville JP, Ward DS, Bloor BC, Maze M. Effects of intravenous dexmedetomidine in humans. I. Sedation, ventilation, and metabolic rate. Anesthesiology 1992; 77:1125-33.

24. Herr DL. Phase IIIB, multicenter, open-label, randomized study comparing the safety/efficacy of dexmedetomidine (Dex) to propofol, for ICU sedation after CABG surgery. Crit Care Med 2000; 28:A124.

25. Venn RM, Bradshaw CJ, Spencer R, Brealey D, Caudwell E, Naughton C, et al. Preliminary UK experience of dexmedetomidine, a novel agent for postoperative sedation in the intensive care unit.
Anaesthesia $1999 ; 54: 1136-42$.

26. Aho MS, Erkola OA, Scheinin H, Lehtinen AM, Korttila KT. Effect of intravenously administered dexmedetomidine on pain after laparoscopic tubal ligation. Anesth Analg 1991;73:112-8.

27. Hindmarch I. Psychomotor function psychoactive drugs. Br J Clin Pharmacol 1980;10:189-209.

How to cite this article: Shah PN, Dongre V, Patil V, Pandya S, Mungantiwar A, Choulwar A. Comparison of post-operative ICU sedation between dexmedetomidine and propofol in Indian population. Indian J Crit Care Med 2014;18:291-6.

Source of Support: Macleods Pharmaceuticals Ltd. Conflict of Interest: Ashish Mungantiwar and Amol Choulwar are employees of Macleods Pharmaceuticals Ltd. who sponsored the clinical trial.Designation mentioned earlier.

\section{"Quick Response Code" link for full text articles}

The journal issue has a unique new feature for reaching to the journal's website without typing a single letter. Each article on its first page has a "Quick Response Code". Using any mobile or other hand-held device with camera and GPRS/other internet source, one can reach to the full text of that particular article on the journal's website. Start a QR-code reading software (see list of free applications from http://tinyurl.com/ yzlh2tc) and point the camera to the QR-code printed in the journal. It will automatically take you to the HTML full text of that article. One can also use a desktop or laptop with web camera for similar functionality. See http://tinyurl.com/2bw7fn3 or http://tinyurl.com/3ysr3me for the free applications. 